\title{
ELECTROCHEMICAL GRINDING OF TITANIUM-CONTAINING MATERIALS
}

\author{
Krzysztof Przystupa', Grzegorz Litak'
}

1 Department of Automation, Lublin University of Technology, Nadbystrzycka 36, 20-618 Lublin, Poland, e-mail:k.przystupa@pollub.pl; g.litak@pollub.pl

Received: 2017.09.27

Accepted: 2017.11.01

Published: 2017.12.05

\begin{abstract}
:
The paper focuses on machining difficult-to-cut materials where a significant component is titanium. The paper discusses a complex process of electrochemical grinding (ECG). A practical example was given by discussing the results of ECG. Selected difficult-to-cut materials, along with their typical ECG properties, were compared. In addition, the paper discusses the phenomenon of micro short-circuits constituting a form of an interference characteristic for the process. The results presented in the paper refer to the phenomenon of a micro short-circuits, i.e. the case when a rapid and uncontrolled electrical discharge occurs in the machining zone. The paper presents examples of recorded micro short-circuits and attempts a time-frequency analysis regarding the occurrence of the disturbance. To reveal the dynamics of the ECG process we applied wavelet analysis.
\end{abstract}

Keywords: hybrid processes, electrochemical grinding (ECG), micro short-circuit, time-frequency analysis

\section{INTRODUCTION}

A large group of hard materials features an extensive collection of those troublesome when machined by conventional methods. Engineers label such materials as "difficult-to-cut". They are characterized by the following features:

- extensive mechanical strength of material maintained in high temperatures,

- relatively low thermal conductivity resulting from a characteristic structure, which naturally hinders free heat transfer.

Titanium alloys and sinters along with Inconel alloys constitute the most popular difficult-tocut materials. When machined, materials of this type require large cutting forces, which results in an immediate growth of temperature. High temperature leads to the surface layer being hardened. As a consequence, machining difficulties increase and specific methods of heat transfer away from the machining zone are required. Machining of difficult-to-cut materials is associated with rapid cutting tools' wear. It results both from the structure of the tool and workpiece. They are composed of virtually the same materials. As a consequence, rapid tools' wear ensues. In some aspects, the degree of wear is comparable with the wear of the workpiece itself.

Large cutting force, rapid tools' wear, high temperature, and relatively thin and fragile walls of the machined object, may often result in deformations. Despite all the above, difficult-to-cut materials' field of application has broadened. At present, they are ubiquitous in aviation and automotive industries, and in manufacturing casts and production of complex and durable elements of machines and devices. In practice, grinding by means of diamond grinding wheels is applied in machining of such elements. The process is possible if both feed rate and machining depth are small.

In case of particularly demanding elements, electrochemical grinding (ECG) is applied. It is a type of a hybrid process combining various types of effect upon the workpiece. In case of ECG, the flow of electrical current through the workpiece is a prerequisite. 


\section{CONVENTIONAL GRINDING}

Designing grinding of difficult-to-cut materials requires particular care when selecting several input values. These values are selected as the first step based on properties of the machined material, its kind, chemical composition, as well as chemical, mechanical and physical characteristics. The selection of grinding medium constitutes the second step. The size and type of grains along with their type (grade), chemical composition, hardness, thermal conductivity, and chemical strength, are decided upon. The step encompasses the selection of binder for the grinding medium as well. Its type, structure, chemical composition, durability, porosity, thermal stability and conductivity ought to be determined. When selecting the grinding medium, its wear resistance, and suitability for regeneration of work surface constitute a significant criterion. Finally, the selection of input values associated with the machine itself ought to be conducted. Initially, cooling method and cooling agent ought to be selected. Then, the following ought to be determined: grinder's rotational speed $V_{s}$, workpiece feed rate $V_{w}$, and grinding depth $a_{p}$. In general, conventional grinding of titanium alloys is associated with lower speeds than in case of cutting other, less demanding materials $[1,2,3]$. Table 1 compiles set-points for conventional grinding.

\section{HYBRID PROCESSES}

When improving grinding, a moment is reached when further increase of the process' efficiency is possible only by means of a change in the process itself. A new type of energy is introduced for that reason. By combining two different types of energy, hybrid processes result in a twofold improvement of efficiency, when compared with the single-energy process. Figure 1 presents a classification of hybrid processes.

The most popular hybrid processes [7], [8] include:

- Vibration-assisted machining (turning [9], milling [10], and drilling [11]).

- Laser-assisted machining (turning [12]).

As far as machining of titanium-containing materials is concerned, EDM/ECM constitutes a significant group of processes. Among these, grinding with cryogenic cooling $\left(\mathrm{T}<150^{\circ} \mathrm{C}\right)$ seems significant [13]. In addition, chemical-, electrochemical-, and erosion-assisted grinding are also of importance.

Despite considerable harmfulness for environment (mainly harmful electrolytes and fumes), ECG occupies the leading position as far as titanium alloys' machining is concerned [14].

The process is conducted as shown in Fig. 2.

When compared with conventional grinding, energy consumption is diminished, and grinding force and tool's wear are decreased. In addition, efficiency is improved significantly. Properties of

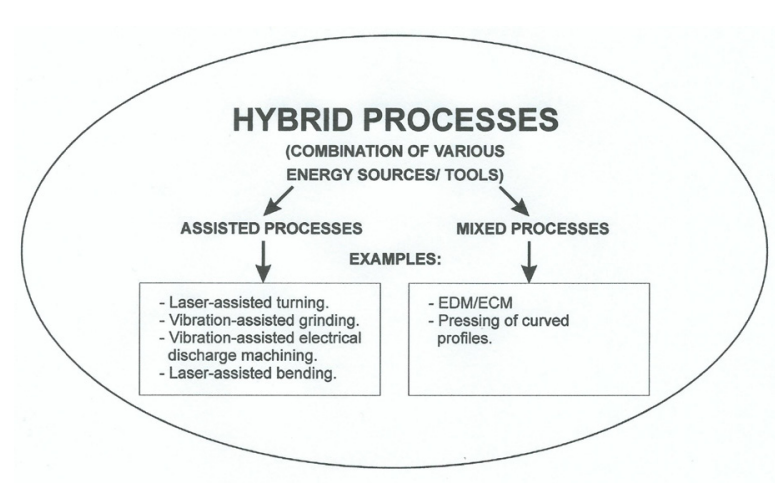

Fig. 1 Classification of hybrid processes.

Table 1. Input values for grinding. Based on literature.

\begin{tabular}{|c|c|c|c|c|}
\hline No. & $\begin{array}{c}\text { Grinder's rotational } \\
\text { speed } V_{s}[\mathrm{~m} / \mathrm{s}]\end{array}$ & Workpiece feed rate $\mathrm{V}_{\mathrm{w}}[\mathrm{m} / \mathrm{s}]$ & Grinding depth $\mathrm{a}_{\mathrm{p}}[\mu \mathrm{m}]$ & Author of publication \\
\hline \multirow{3}{*}{1} & 16 & 0.3 & 10 & $\begin{array}{c}\text { Teicher U., Ghosh A., } \\
\text { Chattopadhyay A.B., Kunatz } \\
\text { K. [4] }\end{array}$ \\
\hline \multirow{3}{*}{2} & 15 & 0.3 & 2 & $\begin{array}{c}\text { Sadeghi M.H., Haddad M.J., } \\
\text { Tawakoli T., Emami M.[5] }\end{array}$ \\
& 17 & 0.5 & 7 & Rosik R., \\
3 & 24 & 0.6 & 10 & Grdulska A.[6] \\
\hline \multirow{3}{*}{4} & 10 & 0.1 & 20 & Rangaswamy P., Terutung H., \\
& 20 & 0.3 & 5 & Jeelani S. \\
\hline
\end{tabular}




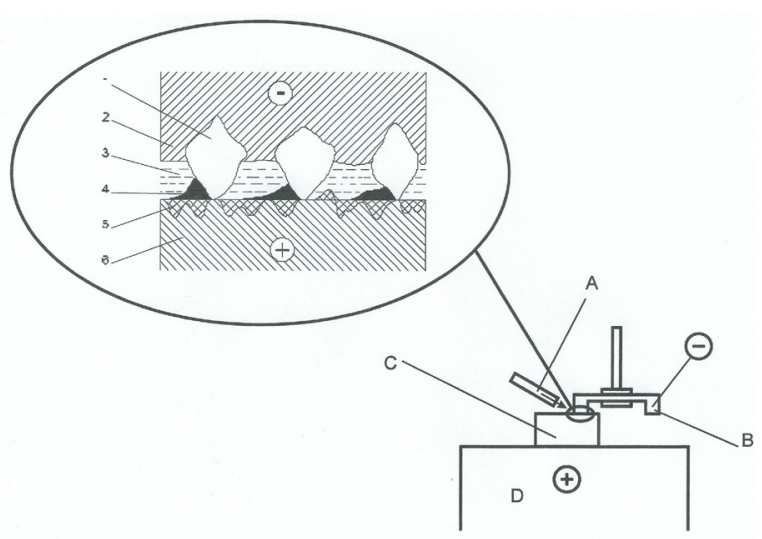

Fig. 2 An outline of electrochemical grinding: Aelectrolyte feed, B- grinding medium, $\mathrm{C}$ - workpiece, D- worktable

1 - diamond grinding grain, 2 - grinding wheel's binder, 3 - electrolyte, 4 - products of dissolution, 5 - cavities in the workpiece, 6 - workpiece.

the outer surface layer depend largely on electric current and voltage. The frequency of electric current is also a factor. The process enables the surface of $\mathrm{R}_{\mathrm{a}}<<0.1 \mu \mathrm{m}$ to be obtained. However, should the voltage between the grinding medium (cathode) and the workpiece (anode) be increased considerably, the quality of the process decreases dramatically. For example, for electric currents of up to $5 \mathrm{~A}$, it is possible to obtain $\mathrm{R}_{\mathrm{a}} \approx 2 \div 3 \mu \mathrm{m}$. However, for up to $100 \mathrm{~A}, \mathrm{R}_{\mathrm{a}}$ increases to even $10 \mu \mathrm{m}$. In case of greater currents (above 10A), craters become visible in the workpiece's surface. For values above 50A, electrical discharge erosion is visible in craters. Electrical discharges can also be observed in the waveform of the current and voltage, and take the form of intense changes of values of both (Fig. 3). In power engineering, a rapid build-up of the current with the simultaneous decrease of voltage is called a short-circuit.

Improvement of the surface quality, i.e. the reduction of $\mathrm{R}_{\mathrm{a}}$ below $0.1 \mu \mathrm{m}$ requires the process to be thoroughly optimized. The optimization revolves around selecting precise voltages between approx. 2 to $4 \mathrm{~V}$ and workpiece feed rate between 5 to $10 \mathrm{~mm} / \mathrm{min}$. In general, low voltage exerts a positive impact upon the quality of the machined surface. Excessive reduction of voltage value (below $2 \mathrm{~V}$ ) results in a decrease of the electrochemical grinding share in the process. However, excessive reduction of working speed results in the emergence of harmful mechanical vibrations [15] in drive systems.

Figure 4 presents the waveform of electric current and voltage for optimized input values.
In the course of research, the highest surface quality $\left(\mathrm{R}_{\mathrm{a}}\right.$ approx. $0.05 \mu \mathrm{m}$ ) was obtained for $6 \mathrm{~A}$ 2 (S3020) grinding medium with silver binding, $\mathrm{NaNO}_{3}(80 \%)$ and $\mathrm{NaCl}(20 \%)$ electrolyte which was supplied in the quantity of $15 \mathrm{l} / \mathrm{min}$ (Fig. 4).

\section{ANALYSIS OF EXPERIMENTAL RESULTS}

In optimal machining conditions, described in Fig. 5, micro short-circuits occur sporadically. On the other hand, in conditions facilitating the occurrence of electrical discharges, intensive grinding wheel's damage occurs. In addition, due to numerous discharges, the process itself is dangerous. As a consequence, in order to analyze micro short-circuits, intermediate conditions were adopted: voltage of $7.5 \mathrm{~V}$, current of $140 \mathrm{~A}$, grinding depth of $10 \mu \mathrm{m}$, and feed rate of $30 \mathrm{~mm} /$ min. Waveforms for the current and voltage on the surface of the workpiece were recorded during the experiment. A section of the recorded data

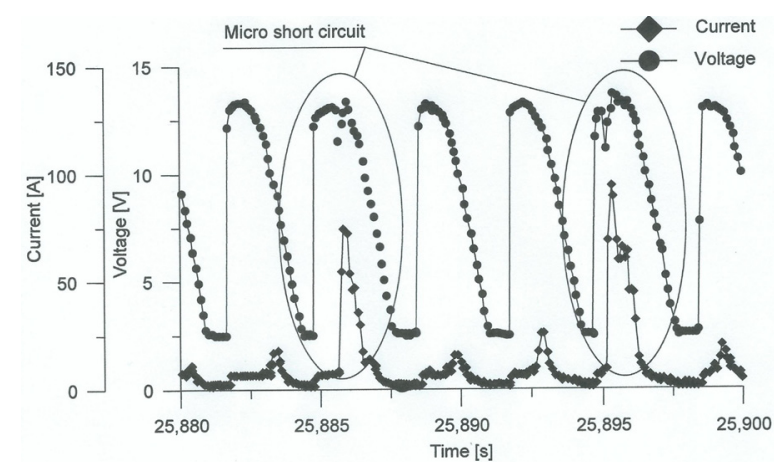

Fig. 3. Discharges in electrochemical grinding (workpiece- Ti-6AI-4V, D160/125 diamond grinding wheel, $10 \% \mathrm{NaNO}_{3}$ electrolyte, input voltage $7.5 \mathrm{~V}$, grinding depth $40 \mu \mathrm{m}$, feed rate $90 \mathrm{~mm} / \mathrm{min}$ ).

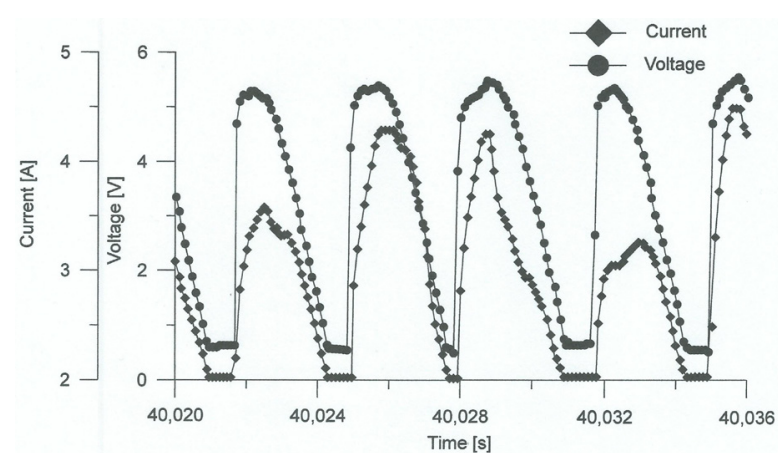

Fig. 4. Waveform of the current and voltage for optimized input values and Ti-6AI-4V material (input voltage $2.5 \mathrm{~V}$, grinding depth $10 \mu \mathrm{m}$, feed rate $7 \mathrm{~mm} / \mathrm{min}$ ). 
was presented in Figs. 5 and 6. The waveform of the voltage (Fig. 5) is periodic with a positive amplitude throughout. It fluctuates both in max. and min. values, which emerges from the structure of power supply system. The waveform of the current (Fig. 6) is similar to the one in voltage as far as its values are concerned. However, the waveform of amplitudes is irregular. The irregularity results from the variable impendance of the machining zone, which emerges due to changes in the properties of the surface.

Our time-frequency analysis adopts the wavelet transform, which enables simultaneous spatio-temporal analysis for both stationary and nonstationary courses. The analysis is based upon the application of scalar products' operations (convolution of functions) of the examined signal

a)

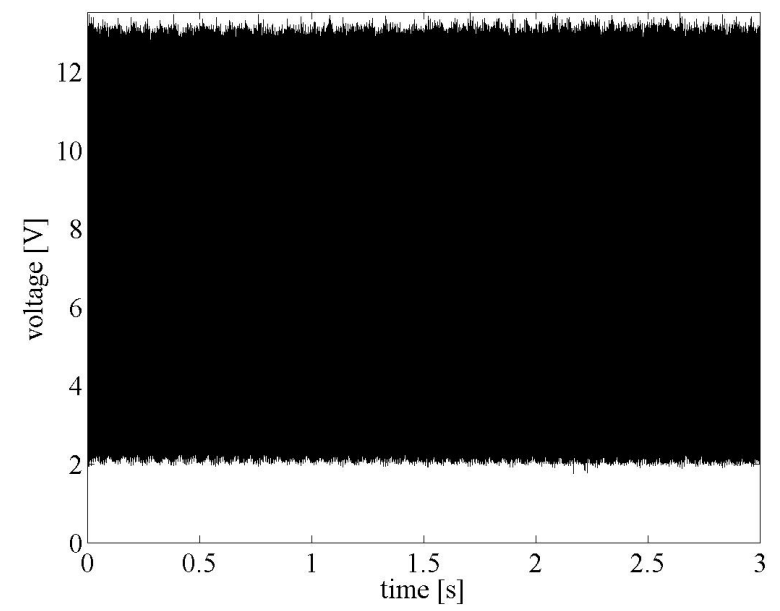

$A c c(t)$ - voltage or current, and the remaining part called the kernel $(\psi(t))[16,17]$.

The corresponding continuous wavelet transformed with respect to the wavelet function $\psi($. $)$ is defined as follows:

$W_{s, n}(A c c)=\sum_{i=1}^{N} \frac{1}{s} \psi\left(\frac{i-n}{s}\right) \frac{\left(A c c\left(t_{i}\right)-<A c c>\right)}{\sigma_{A c c}}$

where: $\left\langle A c c>\right.$ and $\sigma_{A c c}$ are the averages and standard deviations of voltage and current.

Finally, the wavelet $\psi(t)$ is referred to as the mother wavelet, and the letters $s$ and $n$ indicate the scale and the time index, respectively. The wavelet power spectrum (WPS) of the Acctime series is defined as the square modulus of the CWT:

$$
P_{W}=\left|W_{s, n}\right|^{2}
$$

Fig. 5. Waveform of the voltage during electrochemical grinding

b)

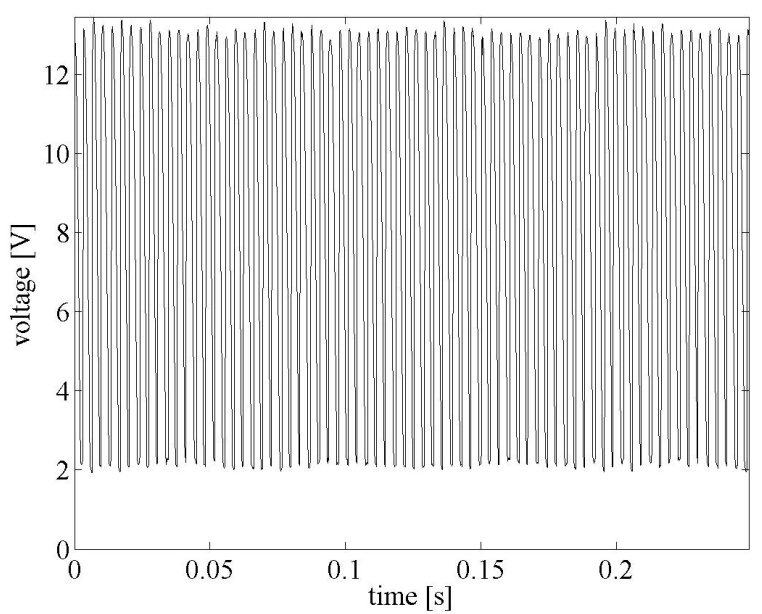

a) time interval of $3 \mathrm{~s}, \mathrm{~b}$ ) time interval of $0.25 \mathrm{~s}$.

a)

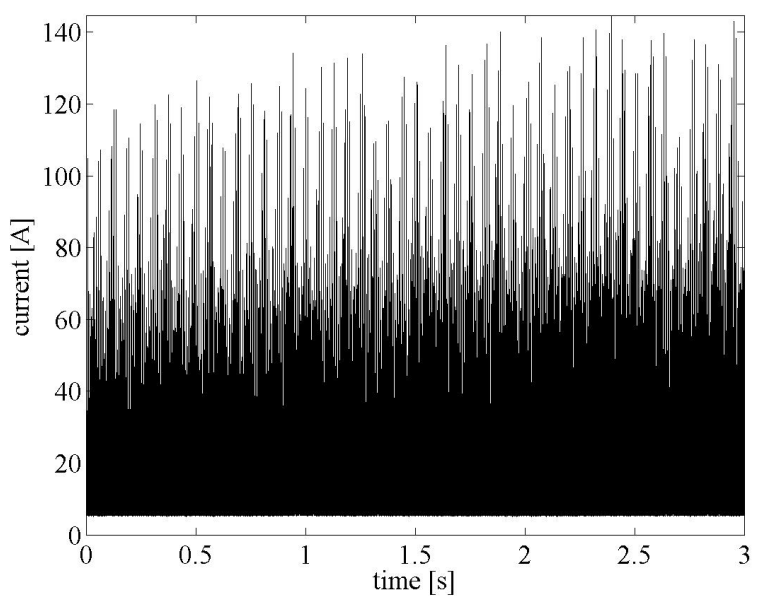

b)

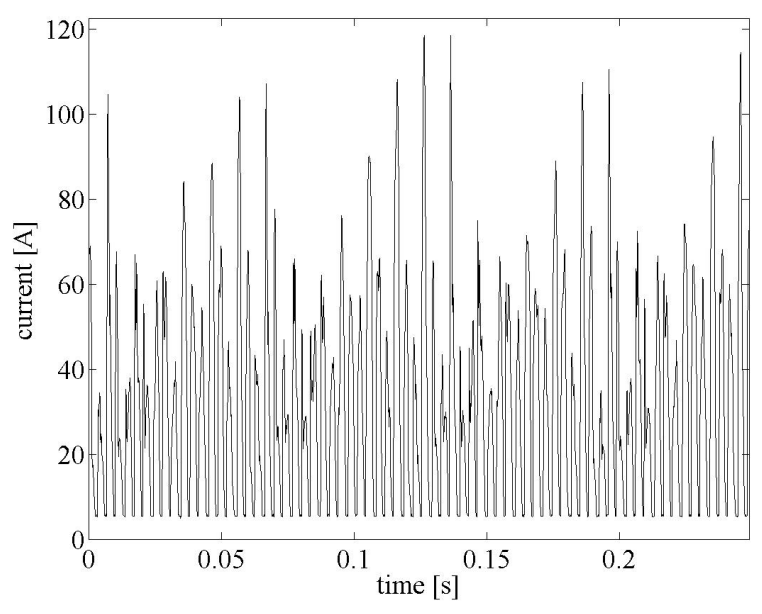

Fig. 6. Waveform of the current during electrochemical grinding a) time interval of $3 \mathrm{~s}, \mathrm{~b}$ ) time interval of $0.25 \mathrm{~s}$. 
In the calculations, the authors used a complex Morlet wavelet as the mother wavelet. The Morlet wavelet consists of a plane wave modulated by a Gaussian function and is described by

$$
\psi(\eta)=\pi^{-\frac{1}{4}} e^{i \theta_{0} \eta} e^{\frac{-\eta^{2}}{2}}
$$

where: $\theta_{0}$ is the central frequency, also referred to as the order of the wavelet, $\eta$ is a renormalized time variable.

The value of $\theta_{0}$ defines the number of oscillations in the wavelet and thus controls the time/ frequency resolutions. In our analysis the authors used $\theta_{0}=6$. This choice provides a good balance between the time and frequency resolutions. Also, for the a.m. choice, the scale is approximately equal to the period, and therefore, the terms scale and the period can be interchanged in order to interpret the results. For general discussion see $[16,17]$. The corresponding results of CWT as the wavelet power spectra are presented in Figs. 7 and 8.

On the basis of time series in Fig. 7 and 8, it can be observed that the frequency of $312 \mathrm{~Hz}$ is dominant. It results from the proper work of the power supply unit. In addition, numerous harmonic frequencies emerge, which is noteworthy. The comparison of Fig. 3, 5, 6, 7, 8 indicates that rapid changes of the current (more transparent) andvoltage (probably micro short-circuits) with the frequency of a few $\mathrm{Hz}$ occur.

\section{CONCLUSIONS}

Hybrid processes have been examined in several R\&D centers. In the course of literature review, no cases comparing the work of a good quality conventional grinding machine and grinding medium with a good quality electrochemical grinder with values set suitably for machining titanium-based materials, were found. Due to low electric conductivity of titanium, electrochemical grinding removes titanium mechanically, and alloying elements (metals of higher electrical conductivity) electrically.

A further consequence of titanium's low electrical conductivity in alloys is the emergence of semiconductors in the course of their machining. This may generate disadvantageous phenomena in electrochemical grinding, including micro short-circuits, which can be observed in the wavelet transform. This phenomenon is disadvantageous with regards to surface quality, however, due to the nature of the process, such interference cannot be avoided.

a)

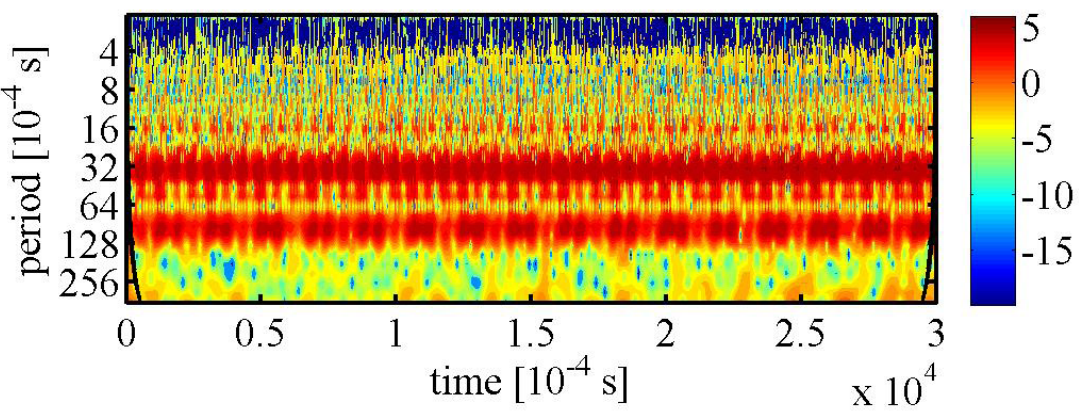

b)

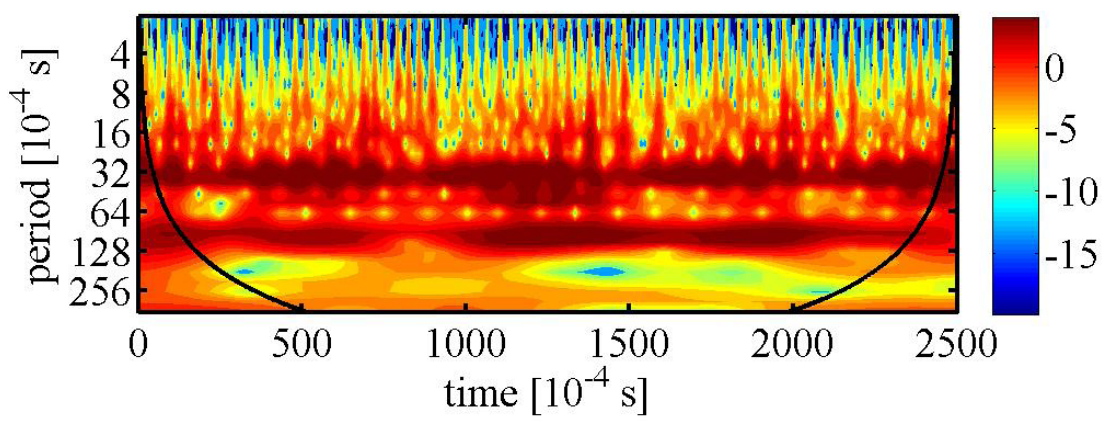

Fig. 7. Waveletpower spectrum (Eq. 2) for recorded current andfor various time intervals a) time interval of $3 \mathrm{~s}$, b) time interval of $0.25 \mathrm{~s}$. The regions below the U-shape curve denote the cone of influence. Outside this cone the edge effects are important and such a region should be removed from discussions. Note that coloures denote the power spectrum magnitudes in the logarithmic scale where the red coloursignals the largest, while the blue colour signals the smallest magnitude. 
a)

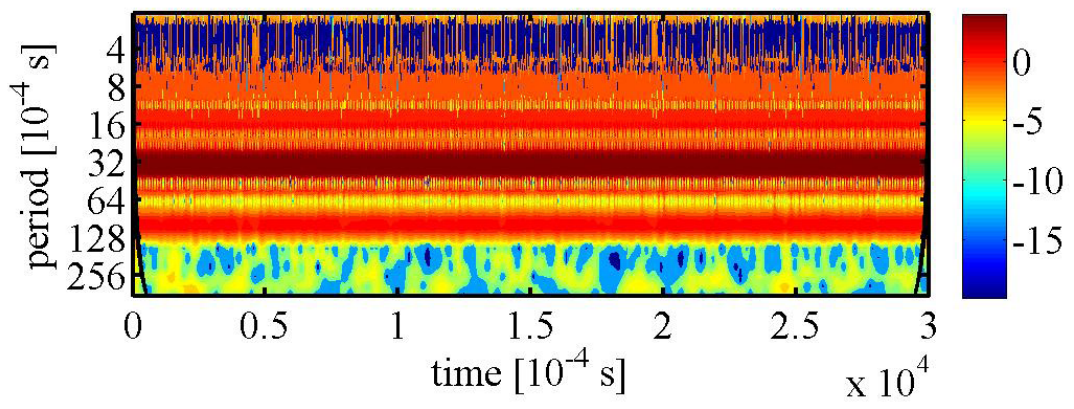

b)

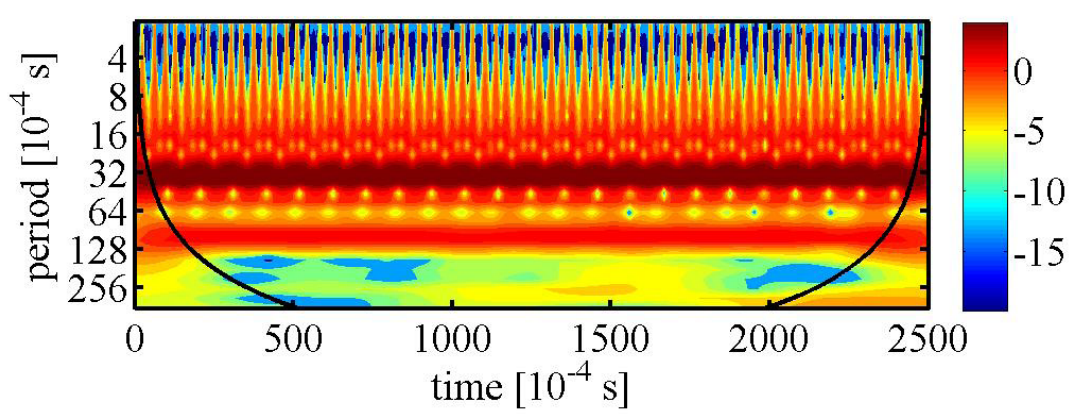

Fig. 8. Waveletpower spectrum (Eq. 2) for recorded voltage and for various time intervals a) time interval of $3 \mathrm{~s}, \mathrm{~b}$ ) time interval of $0.25 \mathrm{~s}$. U-shape curves and coloursare plotted in analogy to Fig. 7.

\section{REFERENCES}

1. Habrat W., Porzycki J., Krok M., Socha E. Wpływ modyfikacji ściernicy z korundu monokrystalicznego na siły skrawania i chropowatość powierzchni podczas szlifowania stopu tytanu Ti6Al4V. Mechanik 8-9 (2015) 122-125.

2. Oczoś K.E., Habrat W. Doskonalenie procesów obróbki ściernej. Cz. I: Quo vadis szlifowanie?. Mechanik 7 (2010) 449-452.

3. Oczoś K.E., Habrat W. Doskonalenie procesów obróbki ściernej. Cz. II: Quo vadis szlifowanie? Mechanik 8-9 (2010) 517-529.

4. Teicher U., Ghosh A., Chattopadhyay A.B., Kunatz K. On the grinability of titanium alloy by brazed type monolayered superabrasive grinding wheels. International Journal of Machine Tools \& Manufacture. 46 (2006) 620-622.

5. Sadeghi M.H., Haddad M.J., Tawakoli T., Emami M. Minimal quantity lubrication $\mathrm{MQL}$ in grinding of Ti-6Al-4V titanium alloy. International Journal of Advanced Manufacturing Technology 44 (2009) 487-500.

6. Rosik R., Grdulska A. Wpływ prędkości szlifowania na topografię powierzchni po procesie szlifowania stopu tytanu. Mechanik 9 (2014) 284-288.

7. Lauwers B., Klocke F., Klink A., Takkaya A.E., Neugebauer R., McIntosh D. Hybrid processes in manufacturing. CIRP Annals - Manufacturing Technology. 63 (2014) 561-583.

8. Szablewski P., Weiss E., Chwalczuk T., Rozwój obróbki materiałów trudnoskrawalnych. Mechanik 8-9 (2016) 1208-1209.
9. Bulla B., Klocke F., Dambon O., Hünten M. Ultrasonic Assisted Diamond Turning of Hardened Steel for Mould Manufacturing. Key Engineering Materials 516 (2012) 437-442.

10. Lian H., Guo Z., Huang Z., Tang Y., Song J. Experimental Research of Al6061 on Ultrasonic Vibration Assisted Micro-Milling. Procedia CIRP6 (2013) 561-564.

11. Neugebauer R., Stoll A. Ultrasonic Application in Drilling. Journal of Materials Processing Technology. 149 (2003) 633-639.

12. Schubert A., Nestler A., Pinternagel S., Zeidler H. Influence of Ultrasonic Vibration Assistance on the Surface Integrity in Turning of the Aluminium Alloy AA2017. Materials Science and Engineering Technology 42 (2011) 658-665.

13. Lauwers B., Klocke F., Klink A., Tekkaya A.E., Neugebauer R., Micintosh D. Hybrid processes in Manufacturing. CIRP Annals - Manufacturing Technology 63 (2014) 561-583.

14. Xu Z., Chen X., Zhou Z., Qin P., Zhu D. Electrochemical machining of high-temperature titanium alloy. Procedia CIRP 42 (2016) 125-130.

15. Rusinek R., Borowiec M., Stability analysis of titanium alloy milling by multiscale entropy and Hurst exponent, European Physical Journal Plus 130 (2015) 194.

16. Torrence C., Compo G.P., A practical guide to wavelet analysis, Bull. Amer. Meteor. Soc. 79 (1998) 61-78.

17. Lonkwic P., Lygas K., Wolszczak P., Molski S., Litak G. Braking deceleration variability of progressive safety gears using statistical and wavelet analyses, Measurement 110 (2017) 90-97. 